\title{
A Study of Anatomical Variations of Median Nerve Formation and Its Relation to the Arteries in the Axilla and Arm
}

\author{
Estudio de las Variaciones Anatómicas en la Formación del Nervio Mediano \\ y su Relación con las Arterias de la Axila y el Brazo
}

\section{B. Samarawickrama}

SAMARAWICKRAMA, M. B. A study of anatomical variations of median nerve formation and its relation to the arteries in the axilla and arm. Int. J. Morphol., 35(2):698-704, 2017.

SUMMARY: Variations of the peripheral nerve formation, communication and distribution are clinically important because such knowledge can be used for proper planning of surgeries and evaluating effects of nerve injuries and clinical imaging. Median nerve is known to have several such variations. However studies done on median nerve in Sri Lankan subjects are spars. The objective of this study was to find out anatomical variations of the median nerve with regards to its variations in roots and relations to the arteries in the axilla and arm. The study was done using 98 upper limbs of 49 formalin fixed cadavers. They were dissected and anatomy of the median nerve formations was studied focusing its variations of the roots and relation to the arteries. Anatomical variations of $\mathrm{MN}$ formation were observed in 33 (33.67\%) upper limbs with 4 bilateral and 25 unilateral variations. These variations were classified broadly in to two groups, variations of roots $(15.3 \%)$ and variation of arterial relations $(18.37 \%)$. There were three types of numerical variations $(9.18 \%)$ and three types of morphological variations $(6.12 \%)$ of roots. The median nerve was found to form in relation to the $2^{\text {nd }}$ part of the axillary artery in $6.12 \%$, abnormal relation to the $3^{\text {rd }}$ part of the axillary artery in $2.04 \%$, normal relation to the $3^{\text {rd }}$ part of the axillary artery in $81.63 \%$, and brachial artery in $10.2 \%$ of the specimens. The current study highlights the presence of different anatomical variations at median nerve formation with regards to its roots and arterial relations and describes three rare forms of anomalies which were not found on literature survey.

KEY WORDS: Median nerve; Roots variations; Abnormal relations; Morphology.

\section{INTRODUCTION}

Anatomy of peripheral nerve formation and distribution can vary. Knowledge of such variations is important in clinical practice for evaluation of nerve injuries without misinterpretation of clinical symptoms and during surgeries of limbs to prevent accidental injuries to nerves. Median nerve is one of the nerves that show multiple variations in its formation, communications and distribution. There are number of studies done on abnormal communications of the median nerve in the axilla and arm. But there are only few studies have been done to find out variations of median nerve formations and its relation to the arteries in the axilla and arm. Therefore the main aim of this study was to identify anatomical variation of the median nerve formation and to find out the site of formation of median nerve in relation to axillary artery or the brachial artery.

\section{MATERIAL AND METHOD}

The study was done within a period of 3 years in the Department of Anatomy Faculty of Medicine University of Ruhuna, Sri Lanka, during undergraduate training. A total number of 98 upper limbs in 49 formalin fixed cadavers which included 29 males and 20 females were dissected according to the Cunningham's manual of practical Anatomy. The brachial plexus was studied meticulously to find out the anatomical variations of formations of the median nerve. Each median nerve was observed in order to find the number of roots, their morphology and relations to the axillary and brachial artery. The site of formation of the median nerve was noted in relation to the parts of the axillary artery (part I, II or III) when the nerve was formed in the axilla. When the origin of the median nerve was in the arm relation to the brachial artery was noted considering whether it was 
proximal or distal to the insertion of the corachobrachialis muscle. Photographs were taken and labeled. The collected data was analyzed and compared with the available data in the literature.

\section{RESULTS}

The normal anatomy of the median nerve formation in relation to the $3^{\text {rd }}$ part of the axillary artery by joining one lateral and one medial roots was observed in $65(66.32 \%)$ upper limbs irrespective of the gender (Fig. 1A). Total number of abnormal pattern of median nerve formation was seen in 33 (33.67\%) upper limbs. Four cadavers had bilateral variations while unilateral variations were observed in 25 cadavers. There were 11 different types of variations which included 5 types of abnormal arterial relations and 6 types of root variations. The roots abnormalities were either numerical variations or morphological variations. Three of these abnormal median nerves had both root variations and abnormal relations to the artery (Table I and Table II).
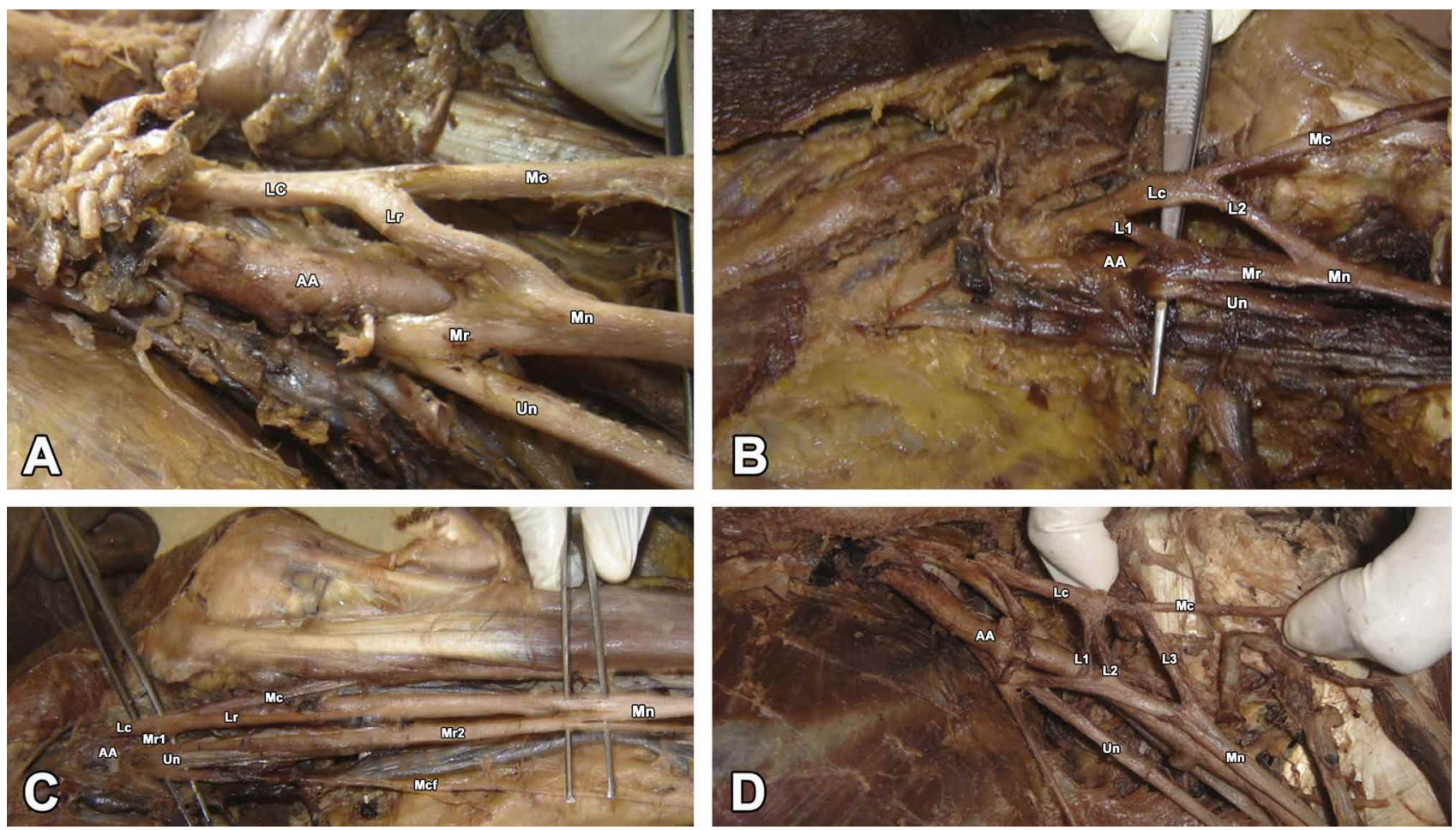

Fig. 1. A. Normal anatomy of the median nerve. B. MN with 2 lateral roots and 1 medial root. C. MN with 2 medial roots and 1 lateral root. D. Median nerve with 4 roots. $\mathrm{Lc}=$ lateral cord; $\mathrm{Mcd}=$ medial cord; $\mathrm{Mr}=$ medial root; $\mathrm{Lr}=$ lateral root; $\mathrm{L} 1=$ lateral root 1 ; $\mathrm{L} 2=$ lateral $\operatorname{root} 2 ; \mathrm{L} 3=$ lateral $\operatorname{root} 3 ; \mathrm{Mr} 1=$ medial $\operatorname{root} 1 ; \mathrm{Mr} 2=$ Medial $\operatorname{root} 2 ; \mathrm{Mn}=$ median nerve; Mc = musculocutaneous nerve; $\mathrm{Un}=$ ulnar nerve; $\mathrm{Mcf}=$ medial cutaneous nerve of forearm; $\mathrm{AA}=$ axillary artery; $\mathrm{BA}=\mathrm{Brachial}$ artery

Tabla I. Arterial relations to the origin of the median nerve (18/33).

\begin{tabular}{lcc}
\hline Abnormality & Total & Percentage \\
\hline Related to the $2 \mathrm{n}^{\mathrm{d}}$ part Axillary artery (AA) & 6 & 6.12 \\
Form in relation to the brachial artery proximal to the insertion of coracobrachialis & 8 & 8.16 \\
Form in relation to the brachial artery distal to the insertion of coracobrachialis artery & 2 & 2.04 \\
Posterior to the $3 \mathrm{r}^{\mathrm{d}}$ part of AA & 1 & 1.02 \\
Compleltely lateral to the $3 \mathrm{r}^{\mathrm{d}}$ part of the AA & 1 & 1.02 \\
Related to the $3 \mathrm{r}^{\mathrm{d}}$ part of AA anteriorly (74) or laterally (6) (normal relation) & 80 & 81.63 \\
Total & 98 & 100 \\
\hline
\end{tabular}


Tabla II. Abnormalities of the roots (15/33)

\begin{tabular}{lcc}
\hline Abnormality & Number & Percentage \\
\hline Three roots with two lateral roots & 6 & 6.12 \\
Three roots with two medial roots & 1 & 1.02 \\
Four roots with three lateral roots & 2 & 2.04 \\
Two lateral roots with absent medial root & 2 & 2.04 \\
Duplicate lateral root with accessory channel & 3 & 3.06 \\
Lateral cord continue as lateral root with absent musculocutaneous nerve & 1 & 1.02 \\
Two roots one medial and one lateral (Normal ) & 83 & 84.69 \\
Total & 98 & 100 \\
\hline
\end{tabular}
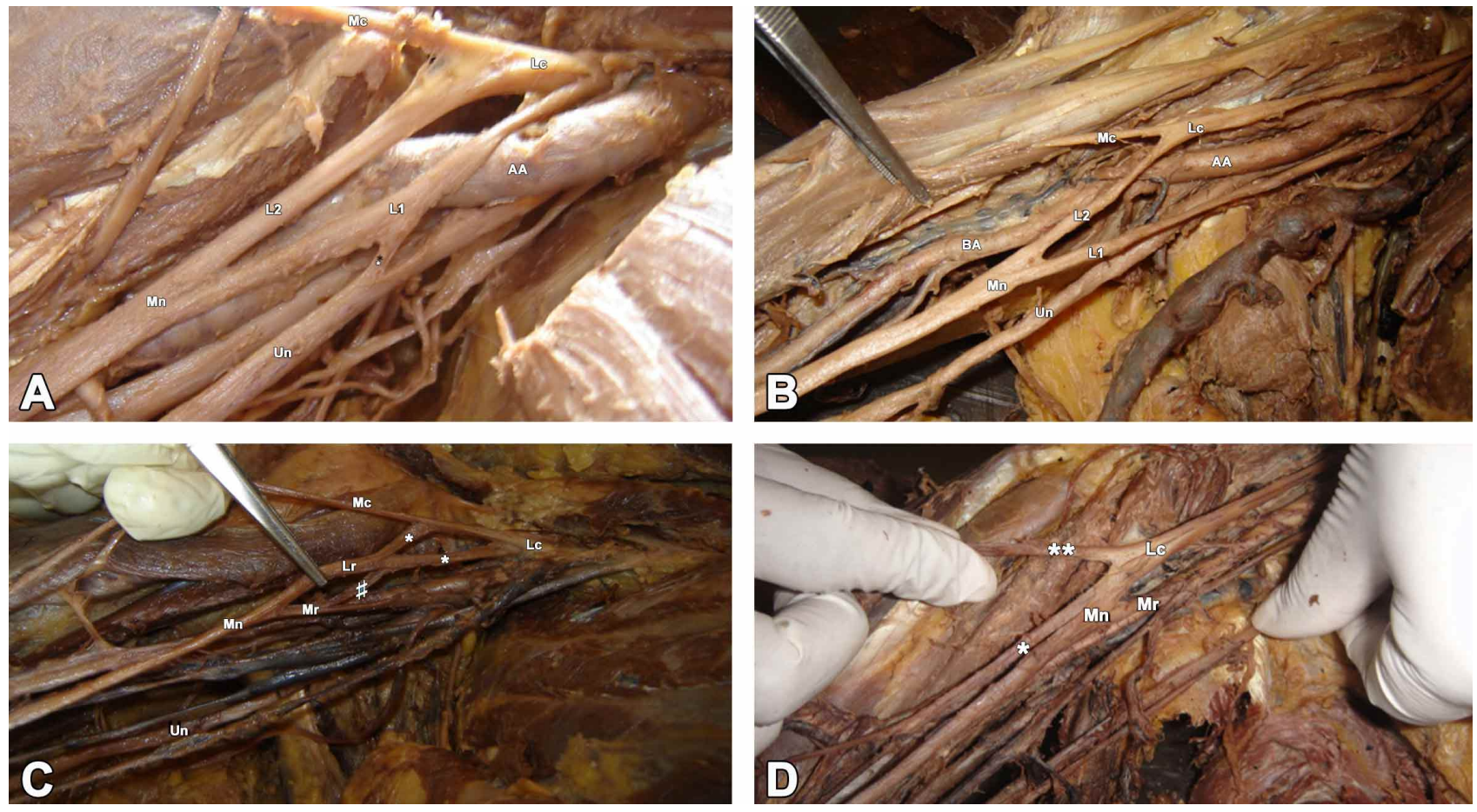

Fig. 2. A. MN with absent medial root (* = communication between Un and L1). B. MN with absent medial root and MN form anterior to the BA. C. MN with duplicate Lr and Accessary channel (* = two divisions of the Lat. Root. \# = accessory nerve channel). D. MN with absent lateral root $(*=$ Nerve to Biceps and, brachialis $* *=$ nerve to coracobrahialis $)$. Lc= lateral cord; $\mathrm{Mcd}=\mathrm{medial}$ cord; $\mathrm{Mr}=$ medial root; $\mathrm{Lr}=$ lateral root; $\mathrm{L} 1=$ lateral $\operatorname{root} 1 ; \mathrm{L} 2=$ lateral $\operatorname{root} 2 ; \mathrm{L} 3=$ lateral $\operatorname{root} 3 ; \mathrm{Mr} 1=$ medial root $1 ; \mathrm{Mr} 2=\mathrm{Medial}$ root 2; Mn = median nerve; $\mathrm{Mc}=$ musculocutaneous nerve; $\mathrm{Un}=$ ulnar nerve; $\mathrm{Mcf}=$ medial cutaneous nerve of forearm; $\mathrm{AA}=$ axillary artery; $\mathrm{BA}=$ Brachial artery

\section{DISCUSSION}

The median nerve $(\mathrm{MN})$ is one of the terminal branches of the brachial plexus which is formed by joining two roots, lateral and medial. The medial root (C8 T1) come from the medial cord and the lateral root (C5-C7) come from the lateral cord of the brachial plexus and embrace the 3rd part of the axillary artery and unite anterior or lateral to it. The nerve then passes medial to the brachial artery on the anterior compartment of the arm (Standring et al., 2005).
Variations of the median nerve have been studied and presented by many authors elsewhere. Studies done on anatomical variations of median nerve is sparse in Sri Lanka. Herath et al. (2014) have described a variation of median nerve of a Sri Lankan subject which was formed by two lateral roots. There are several detail studies done on variations of $\mathrm{MN}$ with regards to its communications with musculocutaneous nerve (MCN) and has mentioned different 
classification systems (Venieratos \& Anagnostopoulou, 1998; Sachdeva \& Singla, 2011; Ramdas et al., 2013). There are several case reports on anatomical variations of roots of the median nerve (Uzun \& Seelig, 2001; Bhanu et al., 2010; Satyanarayana et al., 2010; Talhar et al., 2012; Meshram et al., 2012; Bala et al., 2014; Natsis et al., 2016). But there are only few detail studies on anatomical variations of MN formations and its relation to arteries in the arm and axilla and there is no such classification system as for the communication with MN and MCN. (Bharti et al., 2015) (10 cadavers) and (Badawoud, 2013) (24 cadavers) have done studies on brachial plexuses with regards to anatomical variations and relation in the formation of median nerve. Satyanarayana et al. (2009) described 3 cases of different pattern of MN formation. Channabasanagouda et al. (2013) in his study on anatomical variations of median nerve formations and communications using 50 brachial plexuses and Fazan et al. (2003) in his study of variation in brachial plexus anatomy using 54 upper limbs had described variations of formations of median nerve with regards to its root variations. However, I could not find studies on upper limbs that mainly focused on $\mathrm{MN}$ formation with regards to anomalies of roots and different relations to the arteries in addition to the (Bharti et al.) study. Therefore the main aim of this study was to find out variations of median nerve formation with reference to its number of roots, their morphology and relation of median nerve origin to the arteries in the axilla and arm.

Variations of roots in formation of median nerve. There are several case reports on numerical variation of the roots of the MN. The commonest numerical variation is the formation of the median nerve by three roots instead of two and there are number of case reports on such median nerves (Ibrahim et al., 2005; Surendran et al., 2013; Herath et al.; Patil et al., 2016). Formations of the median nerve by four roots also been reported by few authors (Uzun \& Seelig; Satyanarayana et al., 2009; Meshram et al.). Median nerve is also formed by five roots very rarely (Natsis et al.). There were 7 different patterns of roots variations in the formation of $\mathrm{MN}$ in the current study sample including the normal pattern. The variant roots were divided in to two main types. Type I consists of roots with numerical variations while the type II consists of roots with morphological variations. There were total of $15(15.30 \%)$ median nerves with root anomalies. Out of them, $9.18 \%$ had numerical variations while $6.12 \%$ had morphological variations.

\section{Median nerve with numerical variations of the roots (Type I root variation).}

Median nerves form by three roots: The incidence of this anomaly is reported to be varied from 1- $52 \%$ (Patil et al.).
The incidence of three roots median nerve in the current study was $7.14 \%$. When the median nerve is formed by three roots the additional root can come from either lateral cord (two lateral roots) or medial cord (two medial roots). It is common to have an additional root coming from lateral root as it is evident from several case repots and studies on variations of roots of the median nerve (Ibrahim et al.; Surendran et al.; Herath et al.). Patil et al. have reported a $\mathrm{MN}$ that was formed by three roots and the additional root was originated from medial cord (extra medial root). In his case the median nerve was formed around an abnormal arterial trunk so that the additional root had different relation to the axillary artery. In the current study $6(6.12 \%)$ of this variant had 2 lateral roots while only $1(1.02 \%)$ had two medial roots. Fazan et al. had encountered $28(52 \%) \mathrm{MNs}$ with three lateral roots in their study of 54 upper extremities. None of these median nerves had two medial roots. Therefore it is a rare occurrence to have two medial roots in the formation of MN. All the median nerves in the current study that had two lateral roots were formed in relation to the third part of the axillary artery (Fig. 1B) while the one with additional medial root was formed anterior to the brachial artery distal to the insertion of the coracobrahialis (Fig. 1C). I observed that all the roots of the median nerve including the additional roots were originated from the corresponding cords of the brachial plexus. Fazan et al. had encountered 4 cases of median nerves with two lateral roots in which one of the two roots came from the anterior division of the middle trunk and the other from the lateral cord.

Formation of the nerve by four roots: There were two median nerves that were formed by fusion of four roots in the current study. They occurred as unilateral variations one in a female and the other in a male. One of them was on right side and the other one was on left side. Both of them were formed by three lateral roots and one medial root anterior to the $3^{\text {rd }}$ part of the axillary artery. One of them had its proximal two lateral roots crossing the $2^{\text {nd }}$ part of the axillary artery to join the medial root just medial to the second part of the axillary artery. The third lateral root joined with the preformed median nerve anterior to the third part of the axillary artery to form the median nerve proper (Fig. 1D). In the figure shown here the proximal two lateral roots were smaller than the distal lateral root. But on the other case all three lateral roots were equal in size. Meshram et al. has described a similar case where the first lateral root communicates with the medial root at the level of the first part of the axillary artery. Uzun \& Seelig reported a case of MN with 4 roots in which the distal lateral root joined with the medial root at the proximal arm. One of the three variations of median nerves reported by Satyanarayana $e t$ al. (2009) had four roots in the formation of MN. That MN was formed in relation to the $3^{\text {rd }}$ part of the axillary artery. 
The incidence of this variation is reported to be $3.57 \%$ in the literature (Natsis et al.). The incidence of $\mathrm{MN}$ with 4 roots was $2.04 \%$ in the current study.

Morphological variation of roots of the MN (Type II root variation). I have encountered $6(6.12 \%)$ median nerves with three forms of morphological variations in roots of the median nerve. These include absent medial root, accessory channel and duplicate lateral root and absent lateral root. There were 2 median nerves with absent medial root. The medial cord did not contribute to form the median nerve thus the medial root was absent in both of them. However the morphology of these two nerves was not similar. In the first one (Fig. 2A) both lateral roots arose lateral to the 1st part of the axillary artery and passed lateral to the $2^{\text {nd }}$ part of the axillary artery to form the MN lateral to the $3^{\text {rd }}$ part of the axillary artery. There was a communication branch to the ulnar nerve from the most medial lateral root. In the second one, the most medial lateral root was longer and originated from the lateral root at the beginning of the first part of the axillary artery and crossed the first part of the axillary artery from lateral to medial and passed medial to the rest of the axillary artery. It then joined with the relatively short laterally placed lateral root anterior to the proximal part of the brachial artery. The medial root was absent and there were no connections with the ulnar nerve (Fig. 2B). A case of absent medial root has been described by (Bhanu et al.). However in their case the medial root was absent and the median nerve was formed as a direct continuation of the lateral cord. Both medial and lateral roots were absent. The ulnar nerve communicated with the anterior division of the middle trunk. Searching in Google by using terms "absent medial root of the median nerve" "medial nerve form only by lateral root" "variation of roots of the medial nerve" anatomical variations of median nerve" did not find any other similar reports. This shows the rare occurrence of this variation.

In the second form of morphological variation the MN was formed by two roots medial and lateral and the variation was observed in the lateral root. The lateral root originated from the lateral cord by two divisions (duplicated). The proximal division arose lateral to the $1^{\text {st }}$ part of the axillary artery and the other one arose as one of the terminal branches of the lateral cord lateral to the second part of the axillary artery. Both of these divisions joined to form the lateral root lateral to the $2^{\text {nd }}$ part of the axillary artery. Then the lateral root joined with the medial root to form the median nerve anterior to the $3^{\text {rd }}$ part of the axillary artery. There was a separate nerve channel (accessory nerve channel) which started from the proximal division of the lateral root and crossed the $3^{\text {rd }}$ part of the axillary artery from lateral to medial and joined with the medial root medial to the axillary artery (Fig. 2C).
Google search was done to find out similar cases in the literature using following terms, "duplication of lateral root of median nerve" "duplication of roots of median nerve" "bifid roots of the median nerve" "morphological variations of roots of the media nerve", "accessory communications between roots of the median nerve". There were no similar variations reported in the literature. Nene et al. (2010) has reported a case in which there were three accessory communications between medial cord and the lateral cord of the brachial plexus. In the same case one communication channel connects the lateral root to the medial root. Such accessory communications which crossed the axillary artery may be a source of axillary artery compression (Nene $e t$ al.).

The lateral root of the $\mathrm{MN}$ was absent and the lateral cord continued anterior to the $3^{\text {rd }}$ part of the axillary artery and joined with the medial root to form the $\mathrm{MN}$ in the third form of the morphological variation. The musculocutaneous nerve was absent. The coracobrachialis was supplied by a branch given off by the lateral cord. The biceps and the brachialis were supplied by a single branch originated from the site of the median nerve formation (Fig. 2D). Sarkar \& Saha (2014) have published a similar case in which the musculocutaneous nerve was absent bilaterally and the structures normally supplied by the musculocutaneous nerve were suppliedby the lateral cord and the median nerve.

Arterial relations to the origin of the median nerve. There are several reports on formation of the $\mathrm{MN}$ at different sites of the axilla and arm with different relation to the axillary artery or to the brachial artery (Badawoud; Satyanarayana et al., 2009; Channabasanagouda et al.; Bala et al.; Bharti et $a l$.). In the current study six different relations of median nerve formation to the arteries in the arm and axilla were observed. The normal relationship with $3^{\text {rd }}$ part of the axiilary artery was found in $80(81.63 \%)$ median nerves. Thus 18 $(18.37 \%)$ MNs were found to form with abnormal relations to the axillary artery or to the brachial artery. These abnormal arterial relations to the $\mathrm{MN}$ were divided in to four types. Type I included the median nerve formations with abnormal relation to the $3^{\text {rd }}$ part of the axillary artery. There were 2 $(2.04 \%)$ nerves in this type. Type II were included those nerves formed in relation to the $2^{\text {nd }}$ or the 1 st part of the axillary artery. There were $6(6.12 \%)$ MNs belonging to Type II pattern and all of them were formed in relation to the $2^{\text {nd }}$ part of the axillary artery. Types III and IV were the median nerves, those formed in relation to the brachial artery in the arm. The site of formation was studied in relation to the coracobrahialis muscle insertion. Type III included those nerves formed proximal to the coracobrahialis insertion. Current study sample had $8(8.16 \%)$ MNs formed in relation to the brachial artery proximal to the insertion of the 
coracobrahialis. There were $2(2.04 \%)$ median nerves in Type IV which included those median nerves formed in relation to a point distal to the coracobrahialis insertion. All the nerves in type III and IV were found to form anterior to the brachial artery in the current study. Fazan et al. have found $7 \%$ of their median nerves formed distally in the arm in relation to the brachial artery. According to Natsis et al. the incidence of median nerve formation distal to the axilla has been reported to range from $3.5-40 \%$. The incidence of $\mathrm{MN}$ formation distal to the axillary artery in relation to the brachial artery was $10.2 \%$ in the current study.

According to the findings of the current study it was confirmed that the most common site of median nerve formation is around the $3^{\text {rd }}$ part of the axillary artery. Of the median nerves that were formed with normal relation to the $3^{\text {rd }}$ part of the axillary artery $(78.57 \%)$, majority $71(72.44)$ had formed anterior to the artery while the remaining 6 nerves formed lateral to the artery. In the study done by Channabasanagouda et al., reported 42 median nerves out of the 50 median nerves they studied had originated lateral to the axillary artery. From the remaining 8 nerves 5 were originated anterior to the axillary artery and 3 were originated medial to the axillary artery. However the authors have not mentioned the exact part of the axillary artery to which the median nerve formation was related. Satyanarayana et al. (2009) reported a case of median nerve formed medial to the 3rd part of the axillary artery where the MN passed posterior to the brachial artery in its course. Bharti et al. also reported a case of median nerve formation medial to the axillary artery and that median nerve was formed by three roots. In my study, I did not see any of the nerves related medial to the axillary artery. But there were two rare forms of median nerve axillary artery relationship. The first of this rare one formed posterior to the 3rd part of the axillary artery around an abnormal arterial trunk. A similar case was reported by Patil et al. In their case the median nerve was formed by three roots 2 medial roots and 1 lateral root. One of the medial roots joined with the lateral root posterior to the axillary artery around an abnormal arterial trunk. The other medial root joined with the preformed $\mathrm{MN}$ anterior to the axillary artery. In the current study there were only two roots forming the $\mathrm{MN}$ and the rest of the $\mathrm{MN}$ and the brachial plexus were normal. In the second rare case of my study, the whole brachial plexus was placed lateral to the axillary artery. Therefore, there was no direct relationship between the median nerve formation and the axillary artery. The median nerve was completely lateral and away from the axillary artery. Literature search was done using different terms like "laterally placed brachial plexus", "brachial plexus lateral to the axillary artery", "abnormal position of brachial plexus" "median nerve lateral to the axillary artery" and I could not find any brachial plexus with anomalous relation to the axillary artery in this nature. Therefore I assumed this may be the first case of median nerve reported in this nature.

\section{CONCLUSION}

There are several anatomical variations in the formation of median nerve. These can be broadly divided in to two groups, variation of its roots and variation of arterial relations. Even though there are several publications on numerical variations of the roots of the median nerve, studies on anatomical variations of the median nerve formation itself are spars. There is very little attention has paid to the study of morphological variations of the MN roots and the arterial relations to the $\mathrm{MN}$ formation. The current study highlights the presence of different anatomical variations at median nerve formation and describes some rare form of anomalies. Knowledge of presence of such anatomical variations is important not only to anatomist but also in clinical practice to evaluate nerve injuries and imagine in upper limb and for surgeons to prevent inadvertent damage to nerves during surgery. When considering findings of this study and the findings of the other studies elsewhere, it shows that most of the variations of the median nerve is related to its lateral root.

\section{ACKNOWLEDGEMENTS}

I would like to show my gratitude to the three groups of temporary demonstrators who helped me in dissection and data collection during this three year period.

SAMARAWICKRAMA, M. B. Estudio de las variaciones anatómicas de la formación del nervio mediano y su relación con las arterias de la axila y el brazo. Int. J. Morphol., 35(2):698-704, 2017.

RESUMEN: Las variaciones de la comunicación, formación y distribución del nervio periférico son clínicamente importantes para la planificación adecuada de las cirugías y para evaluar los efectos de las lesiones nerviosas y la imagen clínica. En el nervio mediano se han observado varias de estas variaciones. Sin embargo, son escasos los estudios realizados del nervio mediano en sujetos de Sri Lanka. El objetivo de este estudio fue conocer las variaciones anatómicas del nervio mediano con respecto a sus raíces y las relaciones con las arterias axilar y braquial. El estudio se realizó utilizando 98 miembros superiores de 49 cadáveres fijados con formalina. Se disecó y se estudió la anatomía de las formaciones de los nervios medianos, enfocando sus variaciones a nivel de las raíces y las relaciones con las arterias. Se observaron variaciones anatómicas de la formación de nervio mediano en 33 miembros superiores $(33,67 \%)$ con 4 variaciones bilaterales y 25 unilaterales. Estas variaciones se clasificaron ampliamente en dos gru- 
pos, variaciones de raíces $(15,3 \%)$ y variación de las relaciones arteriales $(18,37 \%)$. Existen tres tipos de variaciones numéricas $(9,18 \%)$ y tres tipos de variaciones morfológicas $(6,12 \%)$ de las raíces. Se encontró que el nervio mediano se formaba en relación con la $2^{\mathrm{a}}$ parte de la arteria axilar en el $6,12 \%$, relación anormal con la $3^{\mathrm{a}}$ parte de la arteria axilar en $2,04 \%$, relación normal con la $3^{\mathrm{a}}$ parte de la arteria axilar en el $81,63 \%$ y braquial en el 10,2 $\%$ de los especímenes. El presente estudio señala la presencia de diferentes variaciones anatómicas en la formación del nervio mediano con respecto a sus raíces y relaciones arteriales y describe tres anomalías raras que no se encontraron en la investigación bibliográfica.

PALABRAS CLAVE: Nervio mediano; Variaciones raices; Relaciones anormales; Morfologia.

\section{REFERENCES}

Badawoud, M. H. M. A study on the anatomical variations of median nerve formation Bahrain. Med. Bull., 25(4):1-5, 2003.

Bala, A.; Sinha, P.; Tamang, B. K. \& Sarda, R. K. Anatomical variation: Median nerve formation - A case vignette. J. Clin. Diagn. Res., 8(6):AD03-04, 2014.

Bhanu, P. S.; Sankar, K. D. \& Susan, P. J. Formation of median nerve without the medial root of medial cord and associated variations of the brachial plexus. Int. J. Anat. Var., 3:27-9, 2010.

Bharti, A.; Paranjpe, V. M. \& Apte, M. V. Variations in the formation and relation of median nerve. Int. J. Anat. Res., 3(3):1298-301, 2015.

Channabasanagouda; Shrish, P.; Shinde, V.; Jevoor, P. S. \& Nidoni, M. A study of anatomical variations of median nerve in human cadavers. Int. J. Biomed. Res., 4(12):682-90, 2013.

Fazan, V. P. S.; Amadeu, A. S.; Caleffi, A. L. \& Rodrigues Filho, O. A. Brachial plexus variations in its formation and main branches. Acta Cir. Bras., 18(Suppl. 5):14-8, 2003.

Herath, H. M. L. Y.; Raayiz, R. M.; Rathnayake, R. M. C. H.; Sandamali, S. P. U.; Amaratunga, H. A. \& Adikari, S. B. Median nerve arising from three roots. Austin J. Anat., 1(3):1011, 2014.

Ibrahim, C. H.; Adnan, E. \& Cem, D. C. Variation between median and musculocutaneous nerves. Internet J. Surg., 6(1), 2005. Available from: https://print.ispub.com/api/0/ispub-article/12283

Meshram, S. W.; Khobragade, K. J.; Pandit, S. V. \& Jadhav, J. S. Four roots of median nerve and its surgical and clinical significance. Int. J. Anat. Var, 5:110-2, 2012.

Natsis, K.; Paraskevas, G. \& Tzika, M. Five roots pattern of median nerve formation. Acta Medica (Hradec Králové), 59(1):26-8, 2016.

Nene, A. R.; Gajendra, K. S. \& Sarma, M. V. R. A rare variant formation of the median nerve. Int. J. Anat. Var., 3:138-40, 2010.

Patil, D. A.; Jadhav, A. S.; Bhingardeve, C. V. \& Katti, A. S. Variation in the formation, communication and distribution of median nerve: A cadaveric study. Asian Pac. J. Health Sci., 3(4):17-22, 2016.

Sachdeva, K \& Singla, R. K. Communication between median and musculocutaneous nerve. J. Morphol. Sci., 28(4):246-9, 2011.

Sarkar, A. \& Saha, A. Bilateral absence of musculocutaneous nerve: A case report. J. Clin. Diagn. Res., 8(9):AD06-07, 2014.

Satyanarayana, N.; Reddy, C. K.; Sunitha, P.; Jayasri, N.; Nitin, V.; Praveen, G.; Guha, R.; Datta, A. K. \& Shaik, M. M. Formation of median nerve by three roots: A case report. J. Coll. Med. Sci. Nepal, 6(1):47-50, 2010.

Satyanarayana, N.; Vishwakarma, N.; Kumar, G. P.; Guha, R.; Dattal, A. K. \& Sunitha, P. Rare variations in the formation of median nerve-embryological basis and clinical significance. Nepal Med. Coll. J., 11(4):287-90, 2009
Standring, S.; Ellis, H. \& Berkovitz, B. K. B. Gray's Anatomy. The Anatomical Basis of Medicine and Surgery. $39^{\text {th }}$ ed. Edinburgh, Elsevier Churchill Livingstone, 2005.

Surendran, S.; Satheesha Nayak, B.; Reghunathan, D.; George, B. M. \& Rao Sirasanagandla, S. Three lateral roots of median nerve: A case report. OA Case Rep., 2(10):97, 2013.

Talhar, S.; Sontakke, B. R.; Bokariya, P.; Tarnekar, A. M. \& Shende, M. R. Bilateral variation in formation of median nerve. IOSR J. Pharm., 2(6):57, 2012.

Uzun, A. \& Seelig, L. L. Jr. A variation in the formation of the median nerve: communicating branch between the musculocutaneous and median nerves in man. Folia Morphol. (Warsz.), 60(2):99-101, 2001.

Venieratos, D. \& Anagnostopoulou, S. Classification of communications between the musculocutaneous and median nerves. Clin. Anat., 11(5):327-31, 1998.

\author{
Corresponding author: \\ Dr. M. B. Samarawickrama \\ Senior Lecturer \\ Department of Anatomy \\ Faculty of Medicine \\ University of Ruhuna \\ Karapitiya \\ Galle \\ SRI LANKA
}

E-mail: samaramb@gmail.com

Received: 27-12-2016

Accepted: 21-03-2017 